\title{
Ideología y escepticismo en George Santayana
}

\section{Ideology and skepticism in George Santayana}

\author{
Rafael Cejudo Córdoba \\ Universidad de Córdoba (España) \\ Ramón Román Alcalá \\ Universidad de Córdoba (España)
}

Recibido: 04-10-2010 Aprobado definitivamente: 16-02-2011

\section{RESUMEN}

Dado que George Santayana mostró simpatía hacia regímenes no democráticos y hay una faceta escéptica en su filosofía, una cuestión ambigua es la de su auténtica ideología política. Para responderla hay que abordar la sugerente teoría crítica de las ideologías que esbozó en su Dominations and Powers, y tener en cuenta su concepción de la filosofía política. Como resultado relativizamos su simpatía hacia regímenes no democráticos, pero al mismo tiempo señalamos las debilidades de su posición política personal así como las ventajas y límites de su doctrina de las ideologías.

\section{PALABRAS CLAVE \\ FILOSOFÍA POLÍTICA, LIBERALISMO, PODER, VIRTUD POLÍTICA}

\begin{abstract}
As George Santayana showed sympathy to non-democratic regimes and there is a skeptical side in his philosophy, the question of which was his real political ideology becomes elusive. To answer it we should turn to the suggestive critical theory of ideologies he outlined in his Dominations and Powers, and take into account his conception of political philosophy. As a result, we attenuate his sympathy to non-democratic regimes but we also point out the flaws of his personal political position as well as the pros and cons of his doctrine of ideologies.
\end{abstract}

CC Contrastes. Revista Internacional de Filosofía, vol. XVII (2012), pp. 119-137. ISSN: 1136-4076

Departamento de Filosofía, Universidad de Málaga, Facultad de Filosofía y Letras Campus de Teatinos, E-29071 Málaga (España) 


\author{
KEYWORDS \\ POLITICAL PHILOSOPHY, LIBERALISM, POWER, POLITICAL VIRTUE.
}

TANTO CRÍTICOS COMO PARTIDARIOS coinciden en que filosofía y vida están indisolublemente mezcladas en George Santayana. En el caso de su filosofía política y de sus opiniones políticas personales, el asunto es especialmente peliagudo porque la recuperación y reivindicación de Santayana tiene que pasar tanto por su filia por el comunismo y el fascismo, como por su desprecio de la democracia liberal. ${ }^{1}$ El estudio de la biografía y la correspondencia de Santayana, ésta última recientemente editada en el marco de sus obras completas, así como el de su extensa y última obra titulada Dominations and Powers, representan sendas tareas aún por hacer. La primera es útil para conocer mejor la relación

1 En España la recepción de la obra de Santayana fue relativamente temprana a través de Antonio Marichalar quien escribió un artículo sobre él en 1923, y tradujo algunas de sus obras ( $c f$. A. Marichalar, «El español-inglés: George Santayana», Revista de Occidente, 3 (1924), pp. 340359 y Santayana, «Carta a Otto Kyllmann», en W. G. Holzberger y H. J. Jr. Saatkamp (eds.), The Letters of George Santayana. Cambridge, Mass.: M.I.T. Press, 2002, p. 184).Zambrano escribió su obituario cuando murió en 1952 (M. Zambrano, «El español Jorge Santayana», Bohemia, 44 (1952), reeditado en Archipiélago. Cuadernos de crítica de la cultura, 70 (2006), pp. 97-100), y poco después Sender lo incluyó entre otros literatos españoles (R. J. Sender, Unamuno, Valle Inclán, Baroja y Santayana: ensayos críticos. México: Ediciones Andrea, 1955). En la misma época también había despertado interés entre algunos intelectuales de la España franquista, y en 1966 Abellán dedicó un libro a su filosofía y Alonso Gamo otro a su obra poética (J. L. Abellán, Santayana (1863-1952). Madrid: Ediciones del Orto, 1966; A. Gamo, Un español en el mundo: Santayana. Poesía y poética. Madrid: Ediciones de cultura hispánica, 1966). La bibliografía en español sobre Santayana consta en J. Beltrán, Celebrar el mundo . Introducción al pensar nómada de George Santayana. Valencia: Publicaciones de la Universidad de Valencia, 2008, pp. 255-266; D. Moreno, Santayana filósofo. La filosofía como forma de vida. Madrid: Trotta, 2007, pp. 219226; VVAA, «Jorge Santayana. Un hombre al margen, un pensamiento central», Archipiélago. Cuadernos de crítica de la cultura, 70 (2006), pp. 104-106. Sobre la recepción de Santayana en español, cf. J. Beltrán, op. cit., pp. 74-81. En 1992 se celebró en Ávila un primer congreso internacional sobre Santayana, y desde entonces se han sucedido en España las traducciones y estudios de su obra. A pesar de ello, todavía la bibliografía española abunda en la reivindicación de su españolidad y quizás por eso mismo, se atenúan las comprometedoras filias ideológicas de Santayana. Frente a esto último pretendemos aquí una consideración desapasionada y neutral tanto de su simpatía por el fascismo y el comunismo, como de su condena del liberalismo. Por otra parte, en Estados Unidos el interés por Santayana se renovó a partir de los años ochenta con la publicación de la revista Overheard in Seville: Bulletin of the Santayana Society desde 1983, y con el inicio en 1986 de la edición crítica de sus obras completas bajo la dirección de Herman J. Saatkamp Jr. 
entre su vida y su actividad filosófica, asunto especialmente importante dado que Santayana consideraba la filosofía una forma de vida. La segunda tarea es indispensable para determinar el significado y el alcance de su filosofía política. Este artículo tiene en cuenta ambos cometidos. La primera sección está dedicada a la relación peculiar entre la vida y la filosofía de Santayana, dado el tono escéptico de esta última y dadas las opiniones políticas que manifestó en la primera. La sección segunda indaga la ideología política de Santayana considerando que una respuesta adecuada requiere tomar en cuenta la doctrina de la ideología política que él mismo elaboró. En la sección tercera se aborda el potencial crítico de esa doctrina de las ideologías mediante su vinculación con las nociones capitales de dominación, poder y virtud. La sección final estudia en qué concepción de la filosofía política se integra dicha doctrina de las ideologías, y cómo tal concepción cuadra con las opiniones políticas particulares que Santayana expresó a lo largo de su vida. El artículo termina con unos comentarios sobre las fortalezas y debilidades ideológicas de Santayana a propósito de la doctrina de las ideologías que está contenida en su filosofía política.

\section{ESCEPTICISMO Y FILOSOFÍA VITAL}

Desde muy antiguo, quizás desde el principio, la filosofía ha tenido la vocación de mejorar la vida de la ciudad, y por lo tanto la tentación de influir en el poder. En muchas ocasiones ese poder ha sido despótico y el filósofo se ha puesto a su servicio. La figura del filósofo «filotiránico», usando la expresión de Lilla, ha sido frecuente en la historia y más aún en el S. XX. ${ }^{2}$ ¿Fue éste el caso de Santayana? Se estableció en Roma definitivamente en 1923, un año después de la llegada de los fascistas al poder, y permaneció voluntariamente en Italia hasta su muerte. No es de extrañar que su obra más extensa e importante sobre política (Dominations and Powers), en la que critica la democracia liberal, fuera acogida con frialdad y sospecha en Estados Unidos, como tampoco es de extrañar que Álvaro D’Ors la recensionara en Arbor en sentido contrario. ${ }^{3} \mathrm{Su}$ discípulo Corliss Lamont le escribió desde Estados Unidos sobre la discusión de si él había sido fascista. Santayana contestó que jamás había militado en partido alguno, que no era lo mismo fascista que asesino, y que la dictadura

2 M. Lilla, Pensadores temerarios. Los intelectuales en la política, tr. N. Catelli. Barcelona: Debate, 2004, p. 168.

3 Álvaro D’Ors, hijo de Eugenio D’Ors, consideró el recelo de Santayana hacia el parlamentarismo «una de las partes más interesantes del libro es aquella en la que el autor hace la crítica del gobierno 'del, por, y para el pueblo' [...] una idea ya muy prodigada en los pueblos que estamos de vuelta de la democracia, pero que en el pensamiento de un Santayana cobra un relieve digno de ser subrayado» (A. D’Ors, «Santayana, sobre dominación y poder», Arbor, 23, 84 (1952), p. 395). 
fascista fue mejor que ningún otro sistema político italiano anterior. El problema en Italia había sido más bien que Mussolini no había estado a la altura. ${ }^{4}$ Tanto en su autobiografía Persons and Places como sobre todo en sus cartas, existen numerosos testimonios de su simpatía por el fascismo y el comunismo. ${ }^{5}$ ¿Qué debemos pensar de todo ello, y más importante, qué relevancia tiene todo ello en la filosofía de Santayana?

En primer lugar, consideramos que desde luego fueron legítimas las suspicacias hacia su posición política, y ello explica interpretaciones un tanto forzadas cuando se quiere defender el conjunto de su figura. ${ }^{6}$ En segundo lugar, Santayana no vio atractivo en la política pues la gestión y la marcha de los asuntos públicos simplemente no le interesaban. Cuando llega a Roma en noviembre de 1921 está teniendo lugar el congreso fundacional del Partido Fascista, y las cartas que Santayana escribe entonces, ya con cincuenta y ocho años, muestran su desconocimiento y desinterés por el asunto. Su opinión es la de un esteta complacido porque las calles de Roma han quedado libres de automóviles. Santayana pensaba que "incluso dentro de la misma iglesia, algunos han nacido para ser monjes y otros para ser obispos; yo nací para monje". S Su valoración de la vida contemplativa conduce lógicamente al rechazo de la política y de las ilusiones

$4 C f$. G. Santayana, «Carta a Corliss Lamont (8 de diciembre de 1950)», en W. G. Holzberger y H. J. J. Saatkamp (eds.), The Letters of George Santayana. Cambridge, Mass.: M.I.T. Press, 2008, vol. VIII, p. 310.

5 Seaton recoge muchos de esos testimonios en J. Seaton, «Santayana on Fascism and English Liberty», Limbo, 29 (2009), pp. 81-100.

6 Por ejemplo Izuzquiza aduce su individualismo intachable a favor de que «al expresar sus dudas sobre el valor de la democracia parlamentaria, Santayana no piensa nunca que la dictadura sea mejor que la democracia. Ello sería un grave error de interpretación en mi opinión» (I. Izuzquiza, George Santayana o la ironía de la materia. Barcelona: Anthropos, 1989, p. 245), y Garrido (uno de quienes más han hecho por el conocimiento de Santayana en España) habla del «insobornable liberalismo de Santayana» (M. Garrido, «Segundos pensamientos de Santayana y Ortega sobre sociedad y política», Limbo, 29 (2009), p. 60). Por su parte, Santayana insiste al final de su vida, tras haber vivido las dos guerras mundiales, en que «si hubo alguna tendencia política que encendió mi cólera (kindled my wrath), ésa fue precisamente la tendencia del liberalismo industrial a rebajar todas las civilizaciones al mismo formato fútil y tedioso» (G. Santayana, Dominations and Powers. Nueva York: Charles Scribner's Sons, 1951, p. vii. En adelante citaremos esta obra como DP). También su opinión del judaísmo provoca sospechas: tuvo buenos amigos judíos, y en 1926 rechazó presidir una asociación antisemita indicando que «usted me considera un personaje enteramente diferente de lo que soy», pero es al menos curioso que su fundador le ofreciera la presidencia ( $c f$. G. Santayana, «Carta a John Jay Chapman», en W. G. Holzberger y H. J. J. Saatkamp (eds.), The Letters of George Santayana. Cambridge, Mass.: M.I.T. Press, 2002, vol. III, pp. 294-295).

7 G. Santayana, loc. cit., p. 295 (salvo cuando se mencione el traductor, todas las obras se citarán por su versión original y con traducción propia). 
de cambio social: "mi filosofía -declaraba- ha sido siempre que el desencanto es el único fundamento seguro para la felicidad". ${ }^{8}$ En tercer lugar, Santayana nunca se comprometió políticamente, si entendemos por tal cosa abdicar de su independencia intelectual poniendo sus ideas al servicio de alguna causa. A veces el resultado pudo ser chocante, como cuando negó toda clase de apoyo a los anarquistas Sacco y Vanzetti. ${ }^{9}$ Finalmente, para Santayana el agente de la filosofía es el espíritu, y éste adopta una visión independendiente (a detached view), separada de su objeto, absolutamente desapasionada. El filósofo se acerca a la política desde lejos, sólo para contemplarla, y propio de esta concepción contemplativa de la filosofía es adoptar frente a la actividad política una mirada libre de valores, al margen de alabanzas o de juicios condenatorios.

Santayana consideraba que la filosofía no es una metodología, ni tampoco una ideología social e histórica, sino más bien expresión de valores y creencias inherentes en la vida natural. ${ }^{10}$ Como Nietzsche, aunque por caminos diferentes, es un caso de filósofo a contracorriente, al margen de las modas, y dispuesto a decir su verdad "más allá del bien y del mal”, también en asuntos políticos. ${ }^{11}$ Aspiraba a la sabiduría de los antiguos, una sabiduría independiente y no comprometida ni con la patria ni con la familia, ni con la moral, la religión o las modas. Como proponía el escepticismo antiguo mediante una analogía médica, se trataría de purgar la vida filosófica (la del espíritu) de todo compromiso cognoscitivo, justo porque la vida humana (la del cuerpo y la mente material) tiene

8 G. Santayana, «Carta a Williams Winslow (4 de noviembre de 1915)», en W. G. Holzberger y H. J. J. Saatkamp (eds.), The Letters of George Santayana. Cambridge, Mass: M.I.T. Press, 2002, vol. II, p. 233. Moreno cita esta afirmación a propósito del estado de ánimo de Santayana a causa de la Primera Guerra Mundial pero al decir Santayana "siempre", creemos que la declaración puede tener un alcance más general (Cf. D. Moreno, ob. cit., pp. 147-148).

9 En 1928 su alumno primero y asistente en Harvard después, H. M. Kallen pidió a Santayana que formara parte de un comité de apoyo a Sacco y Vanzetti. Santayana contestó que «no sé si esos hombres han sido condenados por lo que moralmente no es un crimen, o si son enteramente inocentes. En cualquier caso, es un escándalo retrasar tanto su ejecución, y luego ejecutarlos [...] Es más piadoso para con los condenados, y más ejemplarizante para otros, ejecutarlos inmediatamente como hacen mis amigos los bolcheviques y los fascistas» (G. Santayana, «Carta a Horace M. Kallen (22 de octubre de 1928)», en W. G. Holzberger y H. J. J. Saatkamp (eds.), The Letters of George Santayana. Cambridge, Mass.: M.I.T. Press, 2003, vol. IV, pp. 67-68).

10 El propio Santayana lo afirma con rotundidad : «la filosofía no es una ciencia. Podría ser una vida o un medio de expresión artística» (G. Santayana, «Carta a B.A. G. Fuller (4 de agosto de 1915)», en W. G. Holzberger y H. J. J. Saatkamp (eds.), The Letters of George Santayana. Cambridge, Mass.: M.I.T. Press, 2002, vol. II, p. 223).

11 Dice Garrido que «también el punto de vista de Santayana supo situarse, a su modo, «más allá del bien y del mal» ante el abigarrado paisaje de la historia de la humanidad». M. Garrido, op. cit., p. 61. 
que defender las creencias. ${ }^{12}$ Esta operación del espíritu por la que tomamos distancia de la finitud, puesto que es tan precaria como transitoria, hay que hacerla esbozando una sonrisa. Santayana advertía al comienzo de su Skepticism and Animal Faith que si al presentar su sistema filosófico el lector tenía la tentación de sonreír, «puedo asegurarle que sonrío con él y que mi sistema -al que este volumen es una introducción crítica- difiere mucho, en espíritu y en pretensiones, de lo que normalmente se ajusta a ese nombre». ${ }^{13}$ Con ello Santayana reconocería que, frente a la débil posibilidad de la naturaleza humana de alcanzar un conocimiento verdadero ante la infinita complejidad del Universo, hay que suspender el juicio con una sonrisa escéptica. ${ }^{14}$

Para entender la vida de Santayana se requiere la medicina escéptica de un Sexto Empírico: siendo en todas partes un viajero o un invitado, Santayana podía sentirse a gusto en muchas de ellas, pero sus palabras como huésped del mundo (pensemos en sus vecinos en Ávila, sus amigas de Boston o en el propio Mussolini), no pueden coincidir exactamente con su increencia filosófica. Cuando no consideramos sólo la obra de Santayana sino también su figura, es preciso distinguir una faceta «exotérica» o «popular» propia de su vida mundana, frente a otra distinta en su vida literaria cuya índole sería «esotérica» y escéptica. Los comportamientos, actitudes y declaraciones de Santayana tienen que ser relativizados por las tesis filosóficas que mantuvo en su vida literaria. La distinción es especialmente importante en su caso, dado que Santayana consideraba que una filosofía no puede ser verdadera si no se puede vivir conforme a ella. ${ }^{15}$ Mediante esta distinción trataremos de aclarar que Santayana fuera

$12 \mathrm{Al}$ respecto dice Santayana que «la verdad es un sueño a menos que mi sueño sea verdadero» (G. Santayana, Persons and Places. Cambridge, Mass.: M.I.T. Press, 1986, p. 444). Proponía esta analogía médica Sexto Empírico en Hipotiposis Pirrónicas, I, 206 y también en Matemáticos, VIII, 481.

13 G. Santayana, Scepticism and Animal Faith. Nueva York: Charles Scribner's Sons, 1923, p. v.

14 En ello coincide con Hume, pero también con Sexto Empírico del cual pudo conocer sus obras en los cursos que siguió con Henry Jackson en Cambridge. Según dice Santayana en su correspondencia, durante el curso académico 1896-1897, atendió dos veces por semana a las clases del profesor del Trinity College, quien además le daba una lección privada semanal. No obstante, Santayana declara que el contenido de todas esas clases versaba sólo sobre Platón. $C f$. G. Santayana, «Carta a Josiah Royce (17 de octubre de 1896)» y «Carta a Guy Murchie (17 de julio de 1897)» en W. G. Holzberger y H. J. J. Saatkamp (eds.), The Letters of George Santayana. Cambridge, Mass.: M.I.T. Press, 2001, vol. I, pp. 173 y 185.

15 Decía Santayana que «estoy en filosofía exactamente donde estoy en la vida diaria; no sería honesto que fuera de otra manera». G. Santayana, Scepticism and Animal Faith, ed. cit., p. vi. 
ateo y católico, librepensador y «recuperado» por los intelectuales católicos durante el franquismo. ${ }^{16}$

\section{LA IDEOLOGÍA DE SANTAYANA.}

¿Cuál fue entonces su auténtica ideología política? Trataremos de responder distinguiendo dos aspectos en esta pregunta. Por un lado se trataría de cuáles eran sus afinidades y opiniones políticas, en todo caso débiles y propias de su vida mundana. Al respecto Santayana advirtió que «tengo mis gustos y mis antipatías, de las que no me avergüenzo. Ni renuncio a ellas, ni las impongo, simplemente reconozco que son personales, tradicionales o, dicho de otro modo, accidentales». ${ }^{17}$ Desde luego el liberalismo no fue de su gusto como deja claro tanto lo que dijo y lo que prefirió en su vida mundana, como el esfuerzo que dedicó a demostrar su pobreza y artificialidad en muchas páginas de su vida literaria. El bolchevismo y el fascismo le agradaron durante un tiempo, pero quizá la calificación que más le haga justicia sea la que él mismo se adjudicó en una carta a David Page de 1946. Otros, dice en la carta, consideran que mi concepción política es el fascismo o el falangismo, pero yo me considero un tory. ${ }^{18}$ Por otro lado, y ello es bastante más importante, nuestra pregunta plantea cuál era la concepción que Santayana tenía de la ideología como tal. Y efectivamente Santayana esbozó en Dominations and Powers una doctrina sobre la ideología y sobre la naturaleza ideológica de la política. Mediante ella podemos juzgar más adecuadamente tanto la ideología de Santayana (en el primer sentido de la cuestión), como la relación entre su filosofía política y las ideologías del S. XX.

Aunque no haya una teoría específica de la ideología en la obra de Santayana, como decimos sí existen varias reflexiones explícitas en Dominations and Powers que pueden ser completadas a la luz del resto de su pensamiento. Es lógico que en 1951, tras el inmenso torbellino de la primera mitad del siglo XX, la noción de ideología ocupara un lugar en el pensamiento político de Santayana (junto con otras relacionadas como las de propaganda u opinión pública). ${ }^{19}$ San-

16 Ya nos hemos referido a esta cuestión en la nota $n^{0} 1$. Cf. además C. M. FernándezShaw, «El españolismo de G. Santayana», Revista de estudios políticos, 140 (1965), pp. 41-60; G. Morán, El maestro en el erial. Ortega y Gasset y la cultura del franquismo. Barcelona: Tusquets, 1998.

17 DP, p. viii.

18 G. Santayana, «Carta a David Page (12 de mayo de 1946)», en W. G. Holzberger y H. J. J. Saatkamp (eds.), The Letters of George Santayana. Cambridge, Mass.: M.I.T. Press, 2007, vol. VII, pp. 247-248.

19 Cf. C. García, «Santayana on Public Opinion», Overheard in Seville. Bulletin of the Santayana Society, 23 (2005), pp. 23-27. 
tayana considera que la índole de la vida política es ideológica. Para empezar, lo es en el sentido marxiano de ser la ideología una conciencia falsificadora de la realidad, en último término de la naturaleza o realidad substancial, pero también de una serie de condicionantes que enseguida indicaremos. Mas, a diferencia de la concepción marxiana, no es una falsa conciencia al servicio de la clase social dominante. La ideología, como la ciencia, el arte o la religión, es una representación simbólica de la realidad. Su vinculación con las necesidades y temores de la psicología humana (lo que llama psyche), hace que las ideologías siempre sean mitologías a favor o en contra de los intereses humanos. ${ }^{20}$ Todas tratan de sustituir la insobornable naturaleza por su descripción antropomórfica:

Las ideologías políticas son intentos de reunir esos murmullos privados en un coro tal alto y poderoso como para ahogar el concierto universal de la naturaleza, y convertirlo en un obediente acompañamiento de la voz humana. ${ }^{21}$

Las ideas de que ninguna ideología sea verdadera (pues su discurso nunca es apofántico), de que su alcance sea universal (todo en la política es de alguna manera ideología), y sobre todo su carácter mitológico, emparentan la concepción de Santayana con la de V. Pareto y sobre todo con la de G. Sorel. Según dice el propio Santayana al comienzo de Dominations and Powers, esta obra se fue gestando durante los anteriores cincuenta años, y era una continuación o ampliación del segundo libro de The Life of Reason, dedicado también a cuestiones políticas. Según S. P. Lamprecht muchos de los ensayos que conforman Dominations and Powers muestran similitudes con temas de Scepticism and Animal Faith y de The Realm of Essence, de modo que pueden haber sido redactados en la misma época, en la primera mitad de los años veinte..$^{22} \mathrm{Si}$ esto fuera así, coincidiría con el momento en que Santayana leyó a G. Sorel. Según indica J. McCormick, durante una estancia de Santayana en I Tatti, la villa de su amigo B. Berenson en Fiesole, éste le recomendó vivamente la lectura de Sorel. ${ }^{23}$ Santayana le hizo caso, y en una carta fechada el 19 de marzo de 1925, manifiesta que Sorel le había parecido «nutritivo, a pesar de estar a medio cocinar». ${ }^{24}$

20 DP, p. 14. Cf. J.W. Yolton, «The Psyche as Social Determinant», Journal of Philosophy, 49, 7 (1952),pp. 232-239. Lo que Santayana llama psyche es el sustrato material de esa actividad que ante sí misma aparece como mental, y que constituye por tanto el sujeto político individual. Cf. DP, p. 14; J. Beltrán, op. cit., pp. 208-209; I. Izuzquiza, op. cit., pp. 145-151.

21 DP, p. 15.

22 Lamprecht se basa en la correspondencia de Santayana. $C f$. P. Lamprecht, «Normal Madness and the Political Life», Journal of Philosophy, 497 (1952), pp. 208-213.

23 J. McCormick, George Santayana: A biography. Nueva York: Alfred A. Knopf, 1987, p. 266.

24 G. Santayana, «Carta a Logan Pearsall Smith (19 de marzo de 1925)», en W. G. Holzberger y H. J. J. Saatkamp (eds.), The Letters of George Santayana. Cambridge, Mass.: M.I.T. 
En la biblioteca de Berenson en I Tatti, hoy propiedad de la Universidad de Harvard, en esa fecha de 1925 podían figurar los Matériaux d'une théorie du prolétariat (París, 1919), donde Sorel sostiene que las ideologías sólo son mitos descritos en forma abstracta, y también su Réflexions sur la violence (París, 1912), la obra más influyente de Sorel. ${ }^{25}$ En ella Sorel propone «hacer uso de un cuerpo de imágenes que, mediante la sola intuición, y antes de que se hagan análisis cuidadosos, sea capaz de evocar al completo la masa de sentimientos correspondientes a la lucha del Socialismo contra la sociedad moderna». ${ }^{26}$

Cuando en su ancianidad Santayana retomó el asunto de la política, tras haber vivido la Segunda Guerra Mundial, podía juzgar las ideas de Sorel en su pavorosa efectividad (no en vano Sorel había sido leído por el extremismo de izquierda y de derecha). Sobre el carácter «dramático», no discursivo, atribuido por Sorel a las construcciones ideológicas, Santayana dirá que en la política «los términos usados sólo pueden tener una verdad convencional y dramática». ${ }^{27}$ Santayana defendía que el pueblo no tiene ni una memoria ni una psyche común, de modo que todo interés público, toda voluntad general se debe a la capacidad de las ideologías para aglutinar «la masa de sentimientos» (Sorel), «los murmullos privados en un coro» (Santayana). Y en Santayana como en Sorel, lo ideológico deja de contraponerse a lo científico como sucedía en el pensamiento marxiano.

De todas formas sólo podemos señalar paralelismos y no filiaciones, pues Santayana no menciona a Sorel en Dominations and Powers (aunque esto no es concluyente, dado que no acostumbraba citar sus fuentes). ${ }^{28}$ Más importante es que su pensamiento permite construir una concepción original de la ideología en la que hay diferencias radicales en las funciones atribuidas por Sorel a lo ideológico. Santayana no reduce la filosofía política al estudio de las ideologías históricas y actuales, ni se identifica con ninguna de ellas como hace Sorel, por más que alguna pudiera ser un mito vivificador favorable a la naturaleza. Dominations and Powers fue acogido fríamente no sólo por sus críticas a la democracia liberal norteamericana, sino también porque a principios de los años cincuenta la filosofía política se había convertido en algo muy diferente

Press, 2007, vol. III, p. 242.

25 Ediciones de esas obras y fechas constan actualmente en los fondos de la Biblioteca Berenson de la Universidad de Harvard ( $C f$. http://www.itatti.it/menu3/library.html [5/09/2010]).

26 G. Sorel, Reflections on Violence. Nueva York: AMS Press, 1975, p. 130.

27 DP, p. 143.

28 Sí cita a Bergson, a quien Sorel reconoce como su maestro, aunque en un contexto distinto. Santayana dedicó un estudio a Bergson donde se mostró tan receptivo como crítico (Cf. G. Santayana, Winds of doctrine; studies in contemporary opinion. Nueva York: Charles Scribner's Sons, 1913). 
de lo que Santayana pretendía con su libro. Bajo la influencia del positivismo y el método analítico, la filosofía política anglosajona se ocupaba ya sólo del análisis del lenguaje de la política, mientras que la verdad de los valores, disociada de los hechos, se había convertido en un asunto subjetivo o de consenso social. Dos años después de Dominations and Powers, en 1953, T. D. Weldon publicó su acreditado libro The Vocabulary of Politics, cuyo elocuente título expresaba desde el principio la hostilidad hacia la reflexión sobre la naturaleza íntima de la política. ${ }^{29}$ El pensamiento tradicional sobre los fines de esta última había entrado en crisis, y la función del filósofo ahora debía limitarse a aclarar y precisar el lenguaje político. ${ }^{30}$ A contracorriente, la intención de Santayana con su doctrina de la ideología era continuar lo que Strauss llamó poco después la «solución clásica» de la filosofía política, la indagación en la naturaleza última de lo político. ${ }^{31}$ Es cierto que Santayana defiende que esa naturaleza es ideológica, pero ello no implica hacer una ciencia o análisis político libre de valores. Originalidad de Santayana es que su relativismo axiológico no conlleva equiparar todas las ideologías: unas son poderes a favor de la vida social, otras dominaciones negativas, y en algunos casos el filósofo político puede contemplar incluso ideologías virtuosas.

\section{PARA UNA CRÍTICA DE LAS IDEOLOGÍAS.}

A diferencia de Sorel, la doctrina de Santayana contiene una propuesta de crítica de las ideologías. Puesto que son construcciones simbólicas, a veces útiles y admirables, a veces lo contrario, podemos preguntarnos de qué son signo. Santayana aplica un principio pragmatista de su filosofía consistente en una inversión darwiniana del idealismo. En The Life of Reason lo enuncia diciendo que «toda vida es animal en su origen y enteramente espiritual en sus frutos posibles». ${ }^{32} \mathrm{El}$ error, prosigue el principio, está en adjudicar orígenes

29 T. D. Weldon, The Vocabulary of Politics. Londres: Penguin, 1953.

30 Los títulos coetáneos de Dominations and Powers en lengua inglesa ilustran la crisis de la forma tradicional de hacer filosofía política. Por ejemplo: A. Cobban, «The Decline of Political Theory», Political Science Quarterly, LXVIII 3 (1953), pp. 321-337; J. C. Rees, «The Limitations of Political Theory», Political Studies, II 3 (1954), pp. 242-257; G. E. G. Catlin, «Political Theory: What is it?», Political Science Quarterly, LXXI 1 (1957), pp. 1-29; H. V. Jaffa, «The Case Against Political Theory», Journal of Politics, 222 (1960), pp. 259-275; J. Plamenatz, «The Use of Political Theory», Political Studies, VII 1 (1960), pp. 37-47. En su recensión de Dominations and Powers M. Oakeshott escribió que el libro era "un logro de la imaginación filosófica en una forma a la que estamos desacostumbrados en estos días de minuciosas disecciones" (citado por J. McCormick, op. cit., p. 489. La cursiva es nuestra).

31 L. Strauss, What is Political Philosophy, and Other Studies. Glencoe: Free Press, 1959.

32 G. Santayana, The Life of Reason; Or, The Phases of Human Progress: Reason in 
divinos a objetos naturales, exactamente al revés de lo que ocurre. En el caso de las ideologías se trata de que la psyche y sus construcciones ideológicas son una función del mundo material al que pertenecen, de modo que «los efectos supuestamente producidos por una idea en el mundo, fluyen de las causas por las que esa misma idea fue producida». ${ }^{33}$ Aunque la propia sustancia o naturaleza sólo puede aludirse simbólicamente, nada de esto impide que el análisis de esos tejidos de signos, en la forma de una hermenéutica, pueda revelar su efecto sobre la vida humana. Dice Santayana al respecto que las ideas son proféticas porque «aunque fantásticas, surgen de sus ocasiones y son de ellas símbolos naturales». ${ }^{34}$ Los símbolos políticos pueden ser analizados con más o menos rigor, podemos intentar reducirlos a una simbólica más básica (quizás la económica), y a su vez ésta a alguna otra (pongamos la psicológica), pero nunca es posible llegar a una esencia de la política al margen de cómo la concibamos y designemos. Aunque prosiguiendo la indagación clásica de la esencia de la política, Santayana asume así la problemática moderna de su naturaleza ideológica.

La crítica de las ideologías consiste en distinguir cuándo son un poder y cuándo una dominación. El título de la más extensa obra de Santayana sobre filosofía política (que por cierto fue la última que escribió), es precisamente ése: Dominaciones y poderes (Dominations and Powers). Junto con las Virtudes (denominación también usada en dicha obra), los Poderes y las Dominaciones son jerarquías angélicas. A quien no esté habituado a la ironía de Santayana y a su predilección por la cultura católica, le resultará chocante este préstamo del vocabulario teológico. En general, según afirma en una carta de 1946 poco antes de que Dominations and Powers fuera publicado, la finalidad de la oposición es distinguir entre gobiernos beneficiosos (poderes) y perjudiciales (dominaciones), siendo éstas denominaciones que usaba desde mucho antes, al menos desde 1918. ${ }^{35}$ La etimología de tales términos (todos ellos significan tipos de una misma cosa, esto es, de ángeles), le sirve a Santayana para sugerir que tanto los poderes como las dominaciones y las virtudes influyen en la vida humana de muchas e incontrolables maneras, y para indicar que son distintos por sus efectos pero no por su naturaleza última. La distinción entre los poderes y las dominaciones es «moral» y no «física», se trata de una diferencia normativa que sólo puede trazarse desde la perspectiva espiritual o filosófica. ${ }^{36}$ Aquello que en un momento determinado sirve a una persona o a un grupo para sobrevivir $\mathrm{y}$ crecer en el torbellino de las circunstancias es un poder. Eso mismo puede,

society. Nueva York: Charles Scribner's Sons, 1905, p. 9.

33 DP, p. 147.

34 DP, p. 144.

35 Cfr. J. McCormick, op.cit., pp. 484-485.

36 DP, p. 1. 
ante un cambio de las circunstancias, convertirse en algo que nos arrastre al fracaso, y es entonces cuando debemos calificarlo como dominación en lugar de como poder. Por un lado esta dualidad entre el poder positivo y la dominación negativa en una misma realidad concreta es reveladora del escepticismo con que Santayana miraba la vida política. McCormick cita a este respecto la ambigüedad que atribuía al concepto de libertad (decía Santayana que somos libres de respirar, pero no de no respirar; o que el recién casado es libre de dormir con la novia pero también tiene la obligación de hacerlo) ${ }^{37}$. Lo mismo sucede respecto de las formas de organización política pues ni siquiera las naturalezas angélicas, parece decirnos Santayana, pueden librarse de la caída. Por otro lado, Santayana necesitaba compatibilizar su naturalismo anti-teleológico con la necesidad de hacer valoraciones morales y políticas. Su solución es relativista: una misma ideología, cuyas causas profundas radican en la naturaleza material de toda realidad, puede aparecer como un poder o como una dominación dependiendo de la especificidad de cada caso, porque la piedra de toque del mito político es su utilidad para la vida. Santayana ofrece varios ejemplos concretos. En Dialogues in Limbo dice:

Hay muchas historias falsas contadas tanto por los griegos como por los bárbaros que a veces son útiles para el Estado, pues mediante una artera disposición de signos y sonidos disponen favorablemente las partes internas de los hombres para el trabajo o para la guerra. ${ }^{38}$

En The Life of Reason expone el patriotismo como un mito necesario, como un poder que unifica mediante un esquema de relaciones sociales a la multitud anónima y mutuamente invisible. «Debe surgir -dice Santayana-alguna ficción intelectual que centralice los intereses políticos», y es este mito de algo colectivo el origen del nacionalismo, pero su carácter mitológico no impide que sus efectos sean bien reales. ${ }^{39}$ Contra el liberalismo, existen intereses públicos diferentes de la suma de los intereses individuales, aunque no sean más que una persuasiva ficción. Otro ejemplo consta en Dominations and Powers, donde cita el caso de la teocracia judía, sancionada ideológicamente por el sueño de Jacob, como un poder y no como una dominación. El motivo es que no privó al pueblo de Israel de sus prerrogativas, y así seguiría siendo «mientras los eventos justifiquen la política seguida bajo tales auspicios religiosos». ${ }^{40}$

37 Ejemplos de Santayana citados en J. McCormick, op. cit., p. 485.

38 G. Santayana, Dialogues in Limbo. Londres: Constable and Co., 1925, p. 48.

39 G. Santayana, The Life of Reason; Or, The Phases of Human Progress: Reason in society. Nueva York: Charles Scribner's Sons, 1905, p. 182.

40 DP, p. 312. 
En el fondo su crítica de las ideologías es una aplicación de la doctrina de la «locura normal» (normal madness) expuesta en Dialogues in Limbo. ${ }^{41}$ Consideramos que no es abusivo añadir la ideología política a los sentidos, el amor y la religión como una cuarta clase de locura normal. ${ }^{42}$ Como en esos casos, esta locura será normal, será un poder y una muestra de salud, mientras no reciba el Castigo de la realidad. Las ideologías son una clase de locura, fantasías que ayudan a vivir colectivamente, mientras se mantengan entre los límites de la estupidez y del desatino. Son un producto del Acuerdo entre los individuos mediante el que la fantasía de las psyches se unifican en un cuadro útil. Los «climas de la mente» son variados, $\mathrm{y}$ «toda nación tiene a su propia locura por normal y cabal», dice Santayana. ${ }^{43}$ Precisamente el clima mental cambió extraordinariamente a partir de la Segunda Guerra Mundial, y como indicaremos al final, en la última etapa de su vida Santayana no se apercibió de la magnitud de ese cambio, ni tampoco de la magnitud del castigo que la realidad había impuesto a sus opiniones políticas.

\section{IDEOLOGÍAS Y FILOSOFÍA POLÍTICA.}

La alternativa entre poderes y dominaciones pertenece al plano de la psyche cuya voluntad (Will) aspira inevitablemente a sobrevivir e imponerse en su entorno. Desde el punto de vista del espíritu, sólo tenemos poderes que favorecen las distintas facetas de la naturaleza material. El espíritu (nuestra capacidad reflexiva y contemplativa) puede disfrutar en todo lo que vive del poder por el que aspira a vivir. La psyche, en cambio, absorta en el trajín de la supervivencia y el éxito, sólo vive para la capacidad y la dominación. Además el espíritu puede captar las armonías que ocasional y temporalmente traben varios poderes. Es entonces cuando aparece, literalmente, una virtud. De manera alegórica, Santayana define las virtudes (virtues) por oposición a las dominaciones y a los poderes del modo siguiente: las virtudes son «espíritus que sólo tienen una vida vegetativa o lírica, perfectos en sí mismos, y ajenos a ejercer cualquier influencia sobre otros seres. De manera sin duda no buscada, su existencia puede influir en el orden y el movimiento del mundo, y podrían constituir su mayor belleza. Podrían ser las flores de ese jardín». ${ }^{44}$

Sin influencia planificada en el mundo y surgidas por azar, las virtudes no pertenecen propiamente a la política, dado que ésta es la esfera del poder y la dominación. No obstante podemos hablar de virtudes políticas o ideológicas en

41 Cf. P. Lamprecht, op. cit.

42 De hecho el contexto del ejemplo de las historias útiles para el Estado antes citado es el de la exposición de la locura normal.

43 G. Santayana, Dialogues in Limbo, ed. cit., p. 40.

44 DP, p. 2. 
cuanto que también la esfera política puede suscitarlas ocasionalmente. También la vida política puede engendrar acciones, instituciones, acontecimientos o gestos intrínsecamente valiosos, y que por tanto sólo los ojos del espíritu (de por sí puros y desinteresados) podrán admirar. En consecuencia también la política es un objeto adecuado para la contemplación filosófica, y por eso Santayana inicia Dominations and Powers indicando que aunque no traerá a colación las virtudes a menudo, puesto que en principio son extrañas a la política, tiene la esperanza de que «el lector pueda sentirlas revoloteando siempre silenciosamente sobre las páginas». ${ }^{45}$

Según Moreno la gran cuestión de la filosofía política de Santayana fue si el liberalismo podía ser una virtud. ${ }^{46} \mathrm{Al}$ identificarlo con el industrialismo, el materialismo craso y la mediocridad, defendemos que la respuesta de Santayana fue siempre negativa: no podía serlo dado que iba contra todo lo que representaba la vida del espíritu. También podemos preguntarnos si Santayana consideró que alguna otra ideología política sí podía ser virtuosa. Matizando que las virtudes son temporales, sobrevenidas y no intencionadas, ahora la respuesta es que el aristocratismo antiguo, pero también el comunismo bolchevique y el fascismo fueron, momentáneamente, ideologías virtuosas. ${ }^{47} \mathrm{~A}$ pesar ello su doctrina de la ideología implica rechazar cualquier concepción o programa político que se arroguen la verdad última, como sería el caso del materialismo histórico. Frente a sus pretensiones de verdad histórica, ante sus demostraciones de la lógica subyacente a los procesos sociales, el filósofo esbozará una sonrisa escéptica. Pero también rechaza Santayana la consideración soreliana en particular y fascista en general de que la ideología pueda ponerse al servicio de las fuerzas de la nación o de la raza. La función de la ideología no es la mera propaganda porque su índole no es ilusoria, o al menos no tiene que serlo. Todo tiene su origen en la naturaleza, en la realidad, y la batalla ideológica no es entre visiones alternativas sino entre poderes que sirven a la vida más o menos bien. Por eso, también ante la conversión de la política en fuerza el filósofo esbozará su escéptica sonrisa. Dado que cualquier autoridad es mítica, su crítica de las ideologías no consiste

45 DP, p. 3.

46 Cf. D. Moreno, op. cit., p. 138.

47 Ya hemos citado cómo en su vida mundana manifestó su simpatía por el fascismo, tanto con declaraciones expresas como viviendo voluntaria y gustosamente en Italia durante todo el período fascista. Sobre sus simpatías con el falangismo, $c f$. G. Santayana, Persons and Places, ed. cit., p. 335. Santayana defendió el comunismo en un artículo publicado en la revista The New Frontier en 1934 que luego convirtió en los capítulos Many nations in One Empire («Muchas naciones en un solo imperio») y Through Whom Might Wisdom Rule the World? («¿Mediante quién podría la sabiduría gobernar el mundo?»), ubicados en la parte tercera de Dominations and Powers destinada precisamente al «orden racional de la sociedad» (The Rational Order of Society). 
en comparar la situación actual con un ideal, o en desmontar la legalidad jurídica y social a la luz de una legitimidad racional. Su escepticismo le impide acudir a estándares normativos universales. Estos sólo se contemplan en la perspectiva del espíritu, y por tanto quedan al margen de la política. Su crítica ideológica hay que entenderla a la luz de la misión que establece para la filosofía moral, que consiste en lo siguiente:

El interés que guía al filósofo moral es menos trazar el paso de la humanidad de uno a otro tipo de organización, que distinguir en cada tipo el mal y bien que conllevan. En otras palabras, distinguir los Poderes que trabajan en una civilización, y señalar la Dominación que uno u otro de ellos podría ejercer sobre el resto. ${ }^{48}$

La filosofía, también la filosofía política, es una tarea del espíritu, de modo que sobreviene en la vida de la razón como consecuencia indirecta y no querida del crecimiento y de la acción material natural. Frente al pragmatismo, pero también frente a la concepción más frecuente en la Modernidad, la actividad filosófica es totalmente especulativa y contemplativa. La filosofía política moderna, como propusieron Maquiavelo y Bacon, pretende orientar o incluso construir el orden político. Frente a esta filosofía política militante, Santayana defiende otra ocupada meramente en la contemplación del orden generativo de las sociedades, de su cambio consuetudinario, gradual y no planificado, y atenta a la mágica y breve aparición de las virtudes políticas. Aunque la actitud adecuada sea el desapego (detachment) y el rechazo de la militancia, no es una filosofía «libre de valores» (wertfrei) como la ciencia social weberiana o la filosofía analítica. El espíritu persigue la virtud, y para ello la filosofía política advierte de las dominaciones que causan las ideologías militantes, esas ideologías que persiguen imponer un determinado y exclusivo ideal sobre todos los demás que el orden natural genera en un momento y una sociedad dada. El totalitarismo en grado extremo, pero también la filosofía política preconizada por el liberalismo, están viciadas por esta clase de militancia. Así pues según Santayana la crítica de las ideologías no persigue el paso de la humanidad de uno a otro tipo de organización, pues la razón no establece existencias sino posibilidades. Su objetivo es más modesto: no trata de mejorar conscientemente el futuro sino de apuntalar lo bueno que haya usando las oportunidades del presente. Por ser materialista y escéptico, Santayana es un posibilista desencantado. Sin renunciar a la «razón en la sociedad», descarta las nociones de legitimidad y autoridad a favor de las de poder y dominación. ${ }^{49}$ Aquellas nociones no son siquiera epifenómenos de las luchas de clase, sino meras apariencias. En este punto sí como Maquiavelo,

48 DP, p. 26.

49 La última parte de Dominations and Powers se llama precisamente «el orden racional de la sociedad». 
Santayana trata de captar el equilibrio de fuerzas de cada momento, porque «lo que es virtud en una época es insensatez cuando esa época ya ha pasado, como un viejo que hace el amor». ${ }^{50} \mathrm{Si}$ Prometeo o Alejandro triunfaron, es porque aprovecharon el momento adecuado.

Pero contra Maquiavelo, el naturalismo de Santayana implica un rechazo frontal de la manera moderna de hacer filosofía política. Lo que Santayana estaba defendiendo era retroceder antes del compromiso del sofista Isócrates con el poder y sus efectos mundanos, e incluso antes del compromiso de Platón con el conocimiento que puede dar modelos al poder. Santayana elige la forma más alta del amor platónico, aquella que en El Banquete queda reservada a los que son capaces de una «iniciación perfecta», superior incluso al conocimiento «mayor»y «más bello» que es «la regulación de lo que concierne a las ciudades y familias». ${ }^{51}$ Su planteamiento es el de un «místico castellano», tal como él mismo se calificó. Estas posiciones filosóficas que mantuvo en su vida literaria permiten valorar la simpatía con ideologías totalitarias que manifestó en su vida mundana, y permiten determinar que su ideología política más personal era realmente un conservadurismo tecnocrático donde la técnica sustituiría a la política en aquellas cuestiones resolubles mediante la ciencia natural, mientras que todo lo demás, según declaraba, «lo dejaría al genio peculiar de cada sociedad libre y de cada individuo libre». ${ }^{52}$ La metáfora final de Dominations and Power de un «Instituto Internacional de Economía Racional» instalado en lo más alto de Gibraltar, ilustra este ideal y su fracaso, el cual abre de nuevo el ciclo inevitable de la política.

\section{COMENTARIOS FINALES}

Puesto que el espíritu sólo contempla, la filosofía política de Santayana se acerca al quietismo, lo que en su vida mundana tenía que manifestarse como ironía, adaptabilidad y falta de compromiso. ${ }^{53}$ Mientras tanto, el espíritu tiene que esperar el raro florecimiento de las virtudes políticas, y es aquí donde flaquea

50 G. Santayana, Dialogues in Limbo, ed. cit, p. 41.

51 Platón, Banquete, tr. M. Martínez Hernández. Madrid: Gredos, 1986, p. 259 (209 a).

52 DP, p. 463.

53 Moreno señala que «Santayana estudia el devenir político y social sin pretender acabar con los distintos intereses, sino esperando los raros momentos en que logran armonizarse permitiendo florecer las virtudes» (D. Moreno, op . cit., p. 135). Sobre la ironía y la adaptabilidad, dice Santayana que en el hombre de mundo (¿y qué mejor ejemplo sino él mismo?), «varios virtudes y vicios puede existir, pero no adulterará ninguno de ellos. Algunos de tales virtudes y vicios pueden ser conocidos por sus vecinos, otros no. Sin embargo, la discreción evitará que ninguno aparezca a destiempo en su conversación o su comportamiento. Porque sólo ocasionalmente esas virtudes o vicios podrán ser congruentes con el tema o con la compañía del momento» (DP, p. 306). 
su planteamiento. Cuando era niño Santayana tenía afición a las reproducciones de edificios antiguos y hermosos. ${ }^{54}$ Nunca quiso construirlos ni poseerlos: era en el pasado, en los edificios ya construidos, donde su espíritu buscaba la belleza. Anciano fijó su residencia en Roma, en la Ciudad Eterna que le sugería un presente intemporal donde, decía, «me siento más cerca de mi propio pasado y de todo el pasado y el futuro del mundo». ${ }^{55} \mathrm{Y}$ es que en el pasado es donde el espíritu tiene que esperar las virtudes políticas. No es que Santayana careciera de penetración para diagnosticar la naturaleza y la evolución de las ideologías del presente, es que su doctrina de las ideologías sólo puede diagnosticar las dominaciones y poderes una vez su ciclo ya está cumplido y el cuadro se ha completado. Por eso en los años cincuenta sí advirtió el carácter dominador del comunismo y el fascismo pero, con el dibujo apenas comenzado, no pudo descubrir los poderes del liberalismo democrático.

Santayana fue un anti-demócrata elitista. Prefería una aristocracia, en el sentido literal del término, donde los expertos decidieran los asuntos técnicos y en la que hubiera la mayor libertad posible para la vida del espíritu. Su preferencia era una división del trabajo entre Estado, sociedad e individuo tal que «haya orden donde las condiciones sean conocidas, y libertad allí donde la imaginación trace sus propias leyes». ${ }^{56} \mathrm{~A}$ tenor de estas convicciones, y sobre todo de la doctrina de las ideologías elaborada en Dominations and Powers, queda claro su rechazo del totalitarismo tanto de izquierdas como de derechas. A diferencia de Prometeo y de Alejandro, Mussolini o Stalin construyeron fantasías contrarias a la vida y a la vida de la razón. La mayor limitación de Santayana no se refiere al pasado, pues su propuesta final fue inequívocamente condenatoria de las ideologías totalitarias. La decepción la tenemos cuando miramos al futuro, por así decir, y algo de eso debieron pensar sus coetáneos norteamericanos: Santayana había analizado lúcidamente el mundo destruido por la Segunda Guerra Mundial, pero no había advertido los nuevos poderes emergentes. ${ }^{57}$ Reason in Society, escrito cincuenta años antes, parece clarividente mientras que Dominations and Powers no anuncia apenas nada. Al descartar como circunstanciales e infundadas las categorías de autoridad y legitimidad, Santayana se ocultó las dinámicas de la libertad y la democracia que habían ganado la Segunda Guerra Mundial. Su condena de la Modernidad es tan severa que no advierte de qué manera triunfa tras la segunda Gran Guerra, de modo

54 Cf. G. Santayana, Persons and Places, ed. cit., pp. 143-144.

55 Ibid., p. 536.

56 DP, p. 463.

57 Cf. el número doble que Journal of Philosophy dedicó en marzo de 1952 a la última obra de Santayana (Journal of Philosophy, 49, 7, (1952), pp. 201-238). 
que al estilo de Jünger o Heidegger, sólo le queda «emboscarse» en las calles de Roma.

Hay dos formas de vivir de acuerdo con la naturaleza, y ninguna de vivir contra ella. La primera es la lección del pragmatismo, consistente en sacar el fruto de la máxima de Bacon - «sólo se vence a la naturaleza obedeciéndo$l a »-$, aunque aquí no se trate de vencer sino de vivir. Esta vía es la explicada con maravillosa elocuencia en el relato del Jardín de Autologos de Dialogues in Limbo. El Castigo y el Acuerdo de los que allí se habla significan la conformidad y el compromiso con la experiencia, y son las claves de la acción y la técnica. Ésta es la vía que Santayana sigue en su vida mundana, y para muchos es la única posible. Pero el Espíritu no se compromete, y hay una segunda vía, sólo una, por la que el Espíritu puede dominar absolutamente.$^{58}$ La primera vía es insuficiente pues «en el plano horizontal del flujo y la mutación no puede haber victoria real» ${ }^{59}$ la segunda vía es vertical, es la de la trascendencia del flujo cósmico en la sociedad ideal de las esencias. Ésta es, obviamente, la vía que Santayana sigue en su vida literaria. Teniendo esto en cuenta, volvamos a su deficiente valoración de las posibilidades futuras que la libertad y la democracia brindaban en los años cincuenta. Advertiremos entonces que para Santayana los valores genuinos sólo viven en la perspectiva vertical. La psyche es parte de la naturaleza, al igual que la sociedad surgida de interactuar unas psyches con otras. En ese ámbito, como en otros, surgen valores de los que el Espíritu es testigo, pero en el plano horizontal de la materia y el cambio permanecen estériles, asî que tanto da, en el fondo, una u otra forma de gobierno. Ni en el mundo natural ni en el social hay verdadera evolución, pues el cambio es mera metamorfosis cruel y sin sentido para cualquier espíritu tan olímpico como el de Santayana. Vistas desde lo eterno, desde luego son tan miserables las autocracias como nuestros gobiernos democráticos, pero al mirar desde tan lejos Santayana pasó por alto sus diferencias subestimando las virtudes democráticas. 
RAFAEL CEJUDO CÓRDOBA es Profesor contratado-doctor en el Área del Filosofía Moral del Departamento de CCSS y Humanidades de la Universidad de Córdoba.

\section{Publicaciones recientes:}

«Deontología y racionalidad económica», Revista de filosofía, n 35, 1, 2010 , pp. 153171.

«Republicanismo y teoría de las capacidades. El debate entre P. Pettit y A. Sen sobre la libertad», Contrastes. Revista Internacional de Filosofía, $\mathrm{n}^{\circ}$ 12, 2007, pp. $51-70$.

Lineas de investigación:

Libertad y poder. Deontología y consecuencialismo.

Dirección postal:

Dpto. de CCSS y Humanidades. Facultad de Filosofía y Letras. Universidad de Córdoba. Plaza del Cardenal Salazar, 3. 14071 Córdoba (España).

Dirección electrónica: rafael.cejudo@uco.es

RAMÓN ROMÁN ALCALÁ es Profesor titular en el Área de Filosofía del Dpto. de CCSS y Humanidades de la Universidad de Córdoba.

Publicaciones recientes:

El enigma de la Academia de Platón. Escépticos contra dogmáticos en la Grecia Clásica. Berenice: Córdoba, 2007.

"The skepticism of the new academy: a weak form of platonism?", Philosophical Inquiry, vol. XV, 2003, pp. 199-216.

Líneas de investigación:

Escepticismo antiguo. Estética y teoría del arte

Dirección postal:

Dpto. de CCSS y Humanidades. Facultad de Filosofía y Letras. Universidad de Córdoba.

Plaza del Cardenal Salazar, 3. 14071 Córdoba (España).

Dirección electrónica: fs1roalr@uco.es 
